\title{
What is the role of Ewingella americana in humans? A case report in a healthy 4-year- old girl
}

Susanna Esposito ${ }^{1 *}$ D, Francesco Miconi ${ }^{1}$, Daniela Molinari ${ }^{2}$, Emanuela Savarese ${ }^{1}$, Federica Celi ${ }^{2}$, Livio Marchese ${ }^{3}$, Sara Valloscuro ${ }^{3}$, Giovanni Miconi ${ }^{2}$ and Nicola Principi ${ }^{4}$

\begin{abstract}
Background: Ewingella americana ( $E a)$ is a Gram-negative, lactose-fermenting, oxidase-negative and catalasepositive bacterium that was first described in 1983 as a new genus and species in the family Enterobacteriaceae. It is not known whether $E a$ is a true pathogen or simply an opportunistic infectious agent, as most of the cases have been described in patients at risk.

Case presentation: A 4-year-old girl described here was hospitalized due to a productive cough over the previous 3 weeks and a fever $>38^{\circ} \mathrm{C}$ associated with tachypnea over the previous 2 days. Her familial and personal medical histories were negative for relevant diseases, including respiratory infections. At admission, she was febrile (axillary temperature $39.2^{\circ}$ C) and had dyspnea with retractions, grunting and nasal flaring. A chest examination revealed fine crackling rales in the left upper field associated with bilateral wheezing. A chest X-ray revealed segmental consolidation of the lingula of the left lung. Laboratory tests revealed leukocytosis (15.,800 white blood cells $/ \mathrm{mm}^{3}$ with $50.3 \%$ neutrophils), a slight increase in serum Creactive protein $(11.9 \mathrm{mg} / \mathrm{L})$ and normal procalcitonin values $(<0.12 \mathrm{ng} / \mathrm{mL})$. A nasopharyngeal swab culture did not reveal viral or bacterial respiratory pathogens, including atypical bacteria. A blood culture revealed the presence of a Gramnegative, lactose-fermenting rod that was oxidase negative and catalase positive. The isolate was identified by means of the VITEK ${ }^{\oplus} 2$ identification system (bioMérieux, Firenze, Italy) as Ea. This identification was confirmed by sequencing the $16 \mathrm{~s}$ ribosomal deoxyribonucleic acid (rDNA). The pathogen was sensitive to aminoglycoside, fluoroquinolones, carbapenems, cefotaxime, and ceftazidime but was intermediate against sulfametoxazole/trimethoprim and resistant to amoxicillinclavulanic acid, fosfomycin, and oxacillin. The child was immediately treated orally with amoxicillin-clavulanic acid and erythromycin. Based on the results of a blood culture and sensitivity tests, the amoxicillin-clavulanic acid medication was stopped after 3 days. Erythromycin was continued for a total of 10 days, and the child was discharged after 3 days in the hospital. Follow-up visit 1 month later did not reveal any respiratory problems.
\end{abstract}

Conclusion: This case shows that Ea infections in healthy subjects are mild even in pediatric age, and the need for antibiotic therapy is debated. Cases occurring in subjects with underlying chronic disease can be significantly more complicated and require appropriate antibiotic therapy.

Keywords: Antibiotics, Antinfective therapy, Bacteremic pneumonia, Case report, Community-acquired pneumonia, Ewingella Americana

\footnotetext{
* Correspondence: susanna.esposito@unimi.it

${ }^{1}$ Pediatric Clinic, Department of Surgical and Biomedical Sciences, Università

degli Studi di Perugia, Piazza Menghini 1, 06129 Perugia, Italy

Full list of author information is available at the end of the article
}

(c) The Author(s). 2019 Open Access This article is distributed under the terms of the Creative Commons Attribution 4.0 International License (http://creativecommons.org/licenses/by/4.0/), which permits unrestricted use, distribution, and reproduction in any medium, provided you give appropriate credit to the original author(s) and the source, provide a link to the Creative Commons license, and indicate if changes were made. The Creative Commons Public Domain Dedication waiver (http://creativecommons.org/publicdomain/zero/1.0/) applies to the data made available in this article, unless otherwise stated. 


\section{Background}

Ewingella americana $(E a)$ is a Gram-negative, lactosefermenting, oxidase-negative and catalase-positive bacterium that was first described by Grimont et al. in 1983 as a new genus and species in the family Enterobacteriaceae [1]. Ea is very common in some vegetables and mushrooms, in which it can cause a browning disorder called internal stipe necrosis [2]. However, in humans, the detection of $E a$ in the tissues and bodily fluids of patients with infectious diseases is very uncommon, and the true role of this agent has not been precisely defined. Clinical infections due to $E a$ have been reported to cause peritonitis, conjunctivitis, bacteremia, and pneumonia [3-6]. Colonization in wound and sputum were also reported in patients without causing clinical infection [3, 7]. Sepsis and even death from Waterhouse-Friderichsen syndrome due to $E a$ has also been reported [8]. Ea is seen in adut patients who were immunosuppressed due to diabetes mellitus, bone marrow transplantation, chemotherapy, end stage renal disease, and use of mercaptopurine $[5,6]$. However, though some cases were published in the literature, little is known about the natural habitat of $E a$. As source of infection some authors proposed the citrate solutions prepared in the hospital for coagulations study, the domestic water, the contamination of ice bath, the contamination of catheter or inadequate hand hygiene [9].

$E a$ can survive in water and grow preferentially at $4{ }^{\circ} \mathrm{C}$ and this isolate is not known to be the normal flora of respiratory tract [9]. This paper reports a case of community-acquired bacteremic pneumonia due to $E a$ in an otherwise healthy 4-year-old girl that can be useful for increasing our knowledge regarding the clinical relevance of $E a$.

\section{Case presentation}

The 4-year-old girl described here was hospitalized in the Pediatric Ward of the General Hospital of Terni in the Umbria Region of Italy due to a productive cough over the previous 3 weeks and a fever $>38^{\circ} \mathrm{C}$ associated with tachypnea over the previous 2 days. Her familial and personal medical histories were negative for relevant diseases, including respiratory infections. The child was born at term after a normal pregnancy. At admission, her physical and neurodevelopmental growth were in the normal range. However, she was febrile (axillary temperature $39.2^{\circ} \mathrm{C}$ ) and had dyspnea with retractions, grunting and nasal flaring. An examination revealed a respiratory rate of 40 breaths/min, heart rate of 111 beats/min, oxygen saturation in room air of $96 \%$, and blood pressure of $104 / 68 \mathrm{mmHg}$. A chest examination revealed fine crackling rales in the left upper field associated with bilateral wheezing. All other systems were normal.
Chest radiography and a series of laboratory tests, including a blood culture, complete blood cell count, serum C-reactive protein (CRP) and procalcitonin levels, liver enzymes, renal function markers, and Chlamydophila pneumoniae and Mycoplasma pneumoniae antibody concentrations were performed. Moreover, a nasopharyngeal swab for the identification of respiratory bacteria and a Mantoux test were performed. A chest $\mathrm{X}$-ray revealed segmental consolidation of the lingula of the left lung. Laboratory tests revealed leukocytosis (15,800 white blood cells $/ \mathrm{mm}^{3}$ with $50.3 \%$ neutrophils), a slight increase in serum C-reactive protein $(11.9 \mathrm{mg} / \mathrm{L})$ and normal procalcitonin values $(<0.12 \mathrm{ng} / \mathrm{mL})$. Blood liver enzymes and renal function markers were normal. A nasopharyngeal swab culture did not reveal viral or bacterial respiratory pathogens, including atypical bacteria. The Mantoux test was negative after $48 \mathrm{~h}$, and atypical bacterial antibodies were not detected.

A blood culture revealed the presence of a Gram-negative, lactose-fermenting rod that was oxidase negative and catalase positive. The isolate was identified by means of the VITEK $^{\odot} 2$ identification system (bioMérieux, Firenze, Italy) as $E a$. This identification was confirmed by sequencing the $16 \mathrm{~s}$ ribosomal deoxyribonucleic acid (rDNA) and comparing the result with a previously published genetic sequence. The antimicrobial susceptibility test carried out by disk diffusion method showed susceptibilities against amikacin, ampicillin, cefotaxime, cefoxitin, ceftazidime, ciprofloxacin, gentamicin, imipenem, piperacillin, piperacillin-tazobactam, and tetracycline, but was intermediate against sulfametoxazole/trimethoprim and resistant to amoxicillin-clavulanic acid, fosfomycin, and oxacillin.

Table 1 summarizes clinical, laboratory and radiological findings at admission, during hospitalization and at the follow-up visit. The child was immediately treated orally with amoxicillin-clavulanic acid $(50 \mathrm{mg} / \mathrm{kg} / \mathrm{die}$ of the amoxicillin component in 3 doses) and erythromycin (50 mg/kg/die in 3 divided doses). Moreover, aerosolized beclometasone in saline solution was administered two times per day. The improvement in the patient's respiratory condition was rapid. Two days after hospital admission, the resolution of her respiratory abnormalities was complete, CRP levels returned to normal values, and the aerosolized therapy was stopped. Moreover, based on the results of a blood culture and sensitivity tests, the amoxicillin-clavulanic acid medication was stopped after 3 days. Erythromycin was continued for a total of 10 days, and the child was discharged after 3 days in the hospital. Follow-up visit 1 month later did not reveal any respiratory problems.

Management of the case was approved by the Ethics Committee of General Hospital of Terni, Italy (2018-PED-02). The patients' parents provided their written informed consent for the management 
Table 1 Clinical, laboratory and radiological findings in a 4-year-old girl with community-acquired bacteremic pneumonia

\begin{tabular}{|c|c|c|c|c|}
\hline Findings & Admission & After 2 days & $\begin{array}{l}\text { After } 4 \text { days (at } \\
\text { discharge) }\end{array}$ & After 28 days (follow-up) \\
\hline $\begin{array}{l}\text { Clinical } \\
\text { objectivity }\end{array}$ & $\begin{array}{l}\text { Productive cough, fever, tachypnea, dyspnea with } \\
\text { retractions, grunting, nasal flaring, fine crackling rales in } \\
\text { the left upper field, bilateral wheezing }\end{array}$ & $\begin{array}{l}\text { Resolution of } \\
\text { dyspnea, } \\
\text { improvement of } \\
\text { the rales }\end{array}$ & $\begin{array}{l}\text { Good cardio-respiratory } \\
\text { objectivity, no more rales } \\
\text { at auscultation }\end{array}$ & $\begin{array}{l}\text { Good general conditions } \\
\text { and complete resolution } \\
\text { of symptoms }\end{array}$ \\
\hline $\begin{array}{l}\text { Oxygen } \\
\text { saturation }\end{array}$ & $96 \%$ & $98 \%$ & $99 \%$ & $99 \%$ \\
\hline Chest X-ray & Segmental consolidation of the lingula in the left lung & & & \\
\hline $\begin{array}{l}\text { Leukocytes } \\
\left(\text { cells } / \mathrm{mm}^{3} \text { ) }\right.\end{array}$ & 15,810 & 10,340 & 8600 & \\
\hline $\begin{array}{l}\text { Neutrophils, } \\
\%\end{array}$ & 50.3 & 50.8 & 45 & \\
\hline $\begin{array}{l}\text { Lymphocytes, } \\
\%\end{array}$ & 39.3 & 31.5 & 40 & \\
\hline Monocytes, \% & 7.9 & 9.9 & 9 & \\
\hline Eosinophils, \% & 2.1 & 7.5 & 5 & \\
\hline Basophils, \% & 0.4 & 0.3 & 1 & \\
\hline $\begin{array}{l}\text { Procalcitonin, } \\
\mathrm{ng} / \mathrm{mL}\end{array}$ & $<0.12$ & & & \\
\hline $\begin{array}{l}\text { C reactive } \\
\text { protein, mg/ } \\
\mathrm{dL}\end{array}$ & 1.19 & 1.71 & 0.31 & \\
\hline $\begin{array}{l}\text { IgG anti- } \\
\text { Chlamydia } \\
\text { pneumoniae }\end{array}$ & 0.2 & & & \\
\hline $\begin{array}{l}\text { IgM anti- } \\
\text { Chlamydia } \\
\text { pneumoniae }\end{array}$ & 0.7 & & & \\
\hline $\begin{array}{l}\text { IgG anti- } \\
\text { Mycoplasma } \\
\text { pneumoniae }\end{array}$ & $<0.1$ & & & \\
\hline $\begin{array}{l}\text { IgG anti- } \\
\text { Mycoplasma } \\
\text { pneumoniae }\end{array}$ & 2.4 & & & \\
\hline Blood culture & Positive for Ewingella americana & & & \\
\hline Mantoux Test & Negative & & & \\
\hline
\end{tabular}

of their child and the publication of the case report.

\section{Discussion and conclusion}

$E a$ has been isolated from a variety of clinical specimens, including blood, wound swabs and sputum. Most patients with it are old and/or are suffering from severe underlying conditions, such as complicated surgeries [10], injuries from accidents [11], drug abuse [12], and renal failure [13]. Some patients have had diabetes, received immunosuppressive therapy, were HIV positive, or suffered from other chronic infections [14]. Cases in otherwise healthy subjects are very rare. This is why $E a$ can be considered an opportunistic bacterium. On the other hand, cases with severe clinical manifestations, including sepsis, have been almost exclusively reported in subjects who, due to their age or the presence of an underlying acute or chronic severe clinical condition, could be considered at risk of severe superimposed bacterial infections.

In healthy subjects, $E a$ infections are generally mild and limited to conjunctivitis and, as in the case reported here, respiratory infections with rapid favorable outcomes. Death has been described in only two cases, both in patients with conditions favoring infectious disease development, such as being at an older age and having severe traumatic injuries. The first case was that of a previously healthy old woman who suffered from Waterhouse-Friderichsen syndrome [8], while the second case occurred in a 30-year-old man who developed nosocomial pneumonia following admission to the hospital due to a road traffic accident [11]. However, because of their underlying conditions, in this second case 
it was difficult to determine whether the $E a$ infection was indeed the cause of death [11]. Interestingly, $E a$ infections are even rarer in children than in adults. A case of sepsis in an infant with congenital nephropathy [15] and a case of acute conjunctivitis [16] have been described. This is the first case of CAP due to $E a$ documented in an otherwise healthy child.

The clinical course of this child seems to indicate that in otherwise healthy subjects $E a$ infections are mild and can resolve spontaneously in few days even when antibiotic treatment is not effective in vitro. In this case, antibiotic therapy was chosen according to the recommendations of several official guidelines that indicate that, in hospitalized children $\geq 4$ years old with radiographically documented CAP, the addition of a macrolide to traditional beta-lactam therapy is an acceptable solution when an atypical bacterial etiology cannot be excluded [17]. At admission, blood culture results and serum Chlamydophyla pneumoniae and Mycoplasma pneumoniae antibody levels were not available. Moreover, both the blood neutrophil count and acute phase reactant serum levels were compatible with a potential atypical bacterial etiology. As the etiology could not be determined, combined therapy with amoxicillin-clavulanic acid and erythromycin was prescribed. However, when the results of antibiotic sensitivity tests became available, it was clear that amoxicillin-clavulanic acid could not be effective. In contrast, erythromycin, despite not being evaluated against this patient's pathogen, is generally poorly effective against all Enterobacteriaceae, including Ea [18]. Consequently, it seems unlikely that the very rapid favorable evolution of this case of CAP could be based exclusively on the antibiotic treatments.

However, the development of an $E a$ infection in patients at risk can pose difficult therapeutic problems. In these cases, antibiotics remain mandatory, but the choice is not simple. Usually, $E a$ is considered resistant to several $\beta$-lactamases, mainly first- and second-generation cephalosporins, but sensitive to third- and fourth-generation drugs from the same group [18]. Penicillins have variable sensitivity, which explains why phenotypes with ampicillin and amoxicillin resistance seem to be inconsistent in the literature [18]. Aminoglycosides, fluoroquinolones, and sulfametoxazole/trimethoprim are generally effective. However, cases of multidrug-resistant $E a$ have been described in which there was a failure of the initially prescribed antibiotic therapy. Pound et al. described a case of $E a$ CAP in a 77-year-old female already suffering from a Mycobacterium tuberculosis infection and Crohn's disease; in this case, $E a$ was sensitive only to ticarcillin/clavulanate, cefotetan, and SMX/TMP, and the correct therapy was prescribed only after the results of a sputum culture and microbial sensitivity tests were available [14].
In conclusion, this case shows that $E a$ infections in healthy subjects are mild even in pediatric age, and the need for antibiotic therapy is debated. Cases occurring in subjects with underlying chronic disease can be significantly more complicated and require antibiotic therapy. The choice of the right antimicrobial can be made difficult by the emergence of resistance to first-line drugs.

\section{Abbreviations \\ CAP: Community-acquired pneumonia; Ea: Ewingella americana; rDNA: Ribosomal deoxyribonucleic acid}

\section{Acknowledgments \\ None. \\ Funding \\ This study was partially supported by an unrestricted grant from the World Association for Infectious Diseases and Immunological Disorders (WAidid 2018_04). WAidid had no role in the management of the case and in the preparation of the manuscript.}

Availability of data and materials

All data and material are available in this manuscript.

\section{Authors' contributions}

FM wrote the first draft of the manuscript; DM and ES performed the literature review; FC and GM supervised the patient's management; LM and SV performed the laboratory tests; NP and SE provided a substantial scientific contribution and critically revised the paper. All of the authors have read and approved the final version of the manuscript.

\section{Ethics approval and consent to participate}

Management of the case was approved by the Ethics Committee of Umbria Region, Perugia, Italy (2018-PED-04), and the parents provided written informed consent for the child's management and treatment.

\section{Consent for publication}

The patient's parents provided written informed consent for the publication of this case report.

\section{Competing interests}

SE is an Associate Editor of BMC Infectious Diseases. The authors have no other conflict of interest to declare.

\section{Publisher's Note}

Springer Nature remains neutral with regard to jurisdictional claims in published maps and institutional affiliations.

\section{Author details}

${ }^{1}$ Pediatric Clinic, Department of Surgical and Biomedical Sciences, Università degli Studi di Perugia, Piazza Menghini 1, 06129 Perugia, Italy. ${ }^{2}$ Pediatric

Clinic, Azienda Ospedaliera di Terni, Terni, Italy. ${ }^{3}$ Laboratory Unit, Azienda

Ospedaliera di Terni, Terni, Italy. ${ }^{4}$ Università degli Studi di Milano, Milan, Italy.

Received: 6 January 2019 Accepted: 25 April 2019

Published online: 06 May 2019

\section{References}

1. Grimont PA, Farmer JJ 3rd, Grimont F, Asbury MA, Brenner DJ, Deval C. Ewingella americana gen.Nov., sp.nov., a new Enterobacteriaceae isolated from clinical specimens. Ann Microbiol (Paris). 1983;134A:39-52.

2. Inglis PW, Peberdy JF. Isolation of Ewingella americana from the cultivated mushroom, Agaricus bisporus. Current Microbiol. 1996;33:334-7.

3. Ryoo NH, Ha JS, Jeon DS, Kim JR, Kim HC. A case of pneumonia caused by Ewingella americana in a patient with chronic renal failure. J Korean Med Sci. 2005;20:143-5.

4. Da Costa PS, Tostes MM, de Carvalho Valle LM. A case of keratoconjunctivitis due to Ewingella americana and a review of unusual organisms causing external eye infections. Braz J Infect Dis. 2000;4:262-7. 
5. Kati C, Bibashi E, Kokolina E, Sofianou D. Case of peritonitis caused by Ewingella americana in a patient undergoing continuous ambulatory peritoneal dialysis. J Clin Microbiol. 1999;37:3733-4.

6. Lartigue MF, Nordmann P, Edelstein MV, Cuzon G, Brisse S, Poirel L. Characterization of an extended-spectrum class A $\beta$-lactamase from a novel enterobacterial species taxonomically related to Rahnella spp./Ewingella spp. J Antimicrob Chemother. 2013;68:1733-6.

7. Bear N, Klugman KP, Tobiansky L, Koornhof HJ. Wound colonization by Ewingella americana. J Clin Microbiol. 1986;23:650-1.

8. Tsokos M. Fatal Waterhouse-Friderichsen syndrome due to Ewingella americana infection. Am J Forensic Med Pathol. 2003:41-4.

9. McNeil MM, Davis BJ, Solomon SL, Anderson RL, Shulman ST, Gardner S, Kabat K, Martone WJ. Ewingella americana: recurrent pseudobacteremia from a persistent environmental reservoir. J Clin Microbiol. 1987;25:498-500.

10. Pien FD, Bruce AE. Nosocomial Ewingella americana bacteremia in an intensive care unit. Arch Intern Med. 1986;146:111-2.

11. Bukhari SZ, Hussain WM, Fatani MI, Ashshi AM. Multi-drug resistant Ewingella americana. Saudi Medical J. 2008;29:1051-3.

12. Hassan S, Amer S, Mittal C, Sharma R. Ewingella americana: an emerging true pathogen. Case Rep Infect Dis. 2012;2012:730720.

13. Li L, Shen J, Tao J, Xue Z. Peritonitis caused by Ewingella americana in a patient with peritoneal dialysis: a case report. J Med Case Rep. 2014;8:86

14. Pound MW, Tart SB, Okoye O. Multidrug-resistant Ewingella americana: a case report and review of the literature. Ann Pharmacother. 2007:41:2066-70.

15. Cobos Carrascosa E, Daza Torres A, Campos Aguilera A, Giménez Sánchez F. Sepsis by Ewingella americana in an infant with congenital nephropathy. An Pediatr (Barc). 2014;81:337-8.

16. Maraki S. Acute conjunctivitis caused by Ewingella americana. J Pediatr Ophthalmol Strabismus. 2012;49:e52-4.

17. Esposito S, Cohen R, Domingo JD, Pecurariu OF, Greenberg D, Heininger U, et al. Antibiotic therapy for pediatric community-acquired pneumonia: do we know when, what and for how long to treat? Pediatr Infect Dis J. 2012;31:e78-85.

18. Stock I, Sherwood KJ, Wiedemann B. Natural antibiotic susceptibility of Ewingella americana strains. J Chemother. 2003;15:428-41.

Ready to submit your research? Choose BMC and benefit from:

- fast, convenient online submission

- thorough peer review by experienced researchers in your field

- rapid publication on acceptance

- support for research data, including large and complex data types

- gold Open Access which fosters wider collaboration and increased citations

- maximum visibility for your research: over $100 \mathrm{M}$ website views per year

At $\mathrm{BMC}$, research is always in progress.

Learn more biomedcentral.com/submissions 